\title{
Comportamento Per se de híbridos de capim-elefante para fins energéticos
}

\author{
Bruna Rafaela da Silva Menezes" ${ }^{*}$, Rogério Figueiredo Daher², Geraldo de Amaral Gravina², \\ Romildo Domingos Gottardo², Larissa Scheideger Athayde Schneider², Avelino dos Santos Rocha²
}

'Universidade Federal Rural do Rio de Janeiro, Seropédica, RJ, Brasil

${ }^{2}$ Universidade Estadual do Norte Fluminense, Campos dos Goytacazes, RJ, Brasil

*Autor correspondente, e-mail: brunarafamenezes@hotmail.com

\section{Resumo}

O objetivo deste estudo foi avaliar o comportamento Per se de híbridos de capim-elefante obtidos em esquema de cruzamento em dialelo parcial e seus genitores para fins energéticos por meio de características morfoagronômicas nas estações chuvosa e seca. O experimento foi conduzido na estação experimental da Pesagro-RJ, em Campos dos Goytacazes, em delineamento em blocos ao acaso, com três repetições. Os cruzamentos foram obtidos entre genitores contrastantes em esquema de dialelo parcial 5 (genitores femininos) $\times 5$ (genitores masculinos). Os tratamentos foram os dez genitores, as vinte e cinco combinações híbridas e uma testemunha. Foram efetuados três cortes de avaliações (abril e outubro de 2013 e abril de 2014). As características avaliadas foram: altura das plantas (ALT), em m; diâmetro do colmo (DC), em cm; largura da lâmina foliar (LL), em $\mathrm{cm}$; número de perfilhos por metro linear (NP); porcentagem de matéria seca (\%MS) e produção de matéria seca (PMS), em t.ha ${ }^{-1}$. Foram realizadas as análises de variância e agrupamentos das médias pelo teste de Scott-Knott $(P<0,05)$. Verificou-se que os híbridos $\mathrm{H} 4$ (Cubano Pinda $x$ Taiwan A-144), H7 (Cameroon - Piracicaba x Três Rios), H8 (Cameroon - Piracicaba x Mercker 86-México), H10 (Cameroon - Piracicaba x Roxo), H13 (P241-Piracicaba x Mercker 86-México), H17 (IACCampinas x Três Rios) e H18 (IAC-Campinas x Mercker 86-México) apresentaram alta produção de biomassa.

Palavras-chave: bioenergia, biomassa, Pennisetum purpureum

\section{Per se performance of elephant grass hybrids for energy purposes}

\begin{abstract}
The aim of this study was to evaluate the Per se performance of elephant grass hybrids obtained by partial diallel crossing and also their parents for energy purposes through agronomic traits during rainy and dry seasons. The experiment was conducted at Pesagro experimental station, Campos dos Goytacazes, RJ, Brazil, in randomized blocks, with three repetitions. The crosses were made between contrasting parents in a partial diallel scheme with 5 female parents $x 5$ male parents. The treatments consisted of ten parents, twenty-five hybrid combinations and the control. Three cuts were realized for evaluations (April and October 2013 and April 2014). The characteristics evaluated were: plant height (ALT), in $\mathrm{m}$; stem diameter (SD), in $\mathrm{cm}$; leaf blade width (LB), in $\mathrm{cm}$; number of tillers per linear meter (NP); dry matter percentage (\%DM) and dry matter production (DMP), in t.ha1. Variance analysis were performed and the means were grouped according to Scott-Knott test $(P$ $<0.05$ ). It was oberved that the hybrid H4 (Cuban Pinda x Taiwan A-144), H7 (Cameroon - Piracicaba $x$ Três Rios), H8 (Cameroon - Piracicaba x Mercker 86-Mexico), H10 (Cameroon - Piracicaba x Roxo), H13 (P241-86-Piracicaba x Mercker 86-Mexico), H17 (IAC Campinas x Três Rios) and H18 (IAC-86Campinas $\times$ Mercker 86-Mexico) presented high biomass production.
\end{abstract}

Keywords: bioenergy, biomass, Pennisetum purpureum 


\section{Introdução}

o capim-elefante

(Pennisetum purpureum Schum.) é uma planta de metabolismo $\mathrm{C}_{4^{\prime}}$ ou seja, altamente eficiente na fixação de $\mathrm{CO}_{2}$ (gás carbônico) atmosférico durante o processo da fotossíntese para a formação de biomassa vegetal (Lemus et al., 2002). A biomassa é fonte de energia renovável promissora, pois possui vantagens econômicas e ambientais significativas, ou seja, é de baixo custo e pode ser usada para reduzir as emissões de dióxido de carbono $\left(\mathrm{CO}_{2}\right)$ (Ibrahim et al., 2014).

Com o emprego de culturas perenes para a produção de biomassa e de sistemas eficientes na conversão, cerca de 250 milhões de hectares no mundo poderiam ser utilizados no desenvolvimento de indústria de bioenergia. A melhoria na produção e qualidade da biomassa pode ser obtida com os avanços no melhoramento vegetal (Samson et al., 2005). o estudo das características produtivas em capim-elefante é de grande importância para o sucesso dos programas de melhoramento que visem à elevação do rendimento (Silva et al., 2008).

Com isso, o objetivo deste estudo foi avaliar o comportamento Per se de híbridos de capim-elefante obtidos em esquema de cruzamento em dialelo parcial e seus genitores para fins energéticos por meio de características morfoagronômicas nas estações chuvosa e seca.

\section{Material e Métodos}

O experimento foi realizado no Centro Estadual de Pesquisa em Agroenergia e Aproveitamento de Resíduos, da Pesagro-Rio, em Campos dos Goytacazes, na região Norte Fluminense, situada a $21^{\circ} 19^{\prime} 23^{\prime \prime}$ de latitude Sul e $41^{\circ} 19^{\prime} 40^{\prime \prime}$ de longitude Oeste, com altitude de $20 \mathrm{~m}$, e o clima classificado como do tipo $A_{w}$ de Koppen. O solo é classificado como argissolo distrófico. A precipitação pluvial registrada durante a execução do experimento no campo (a partir do corte de uniformização) encontra-se representada na Figura 1.

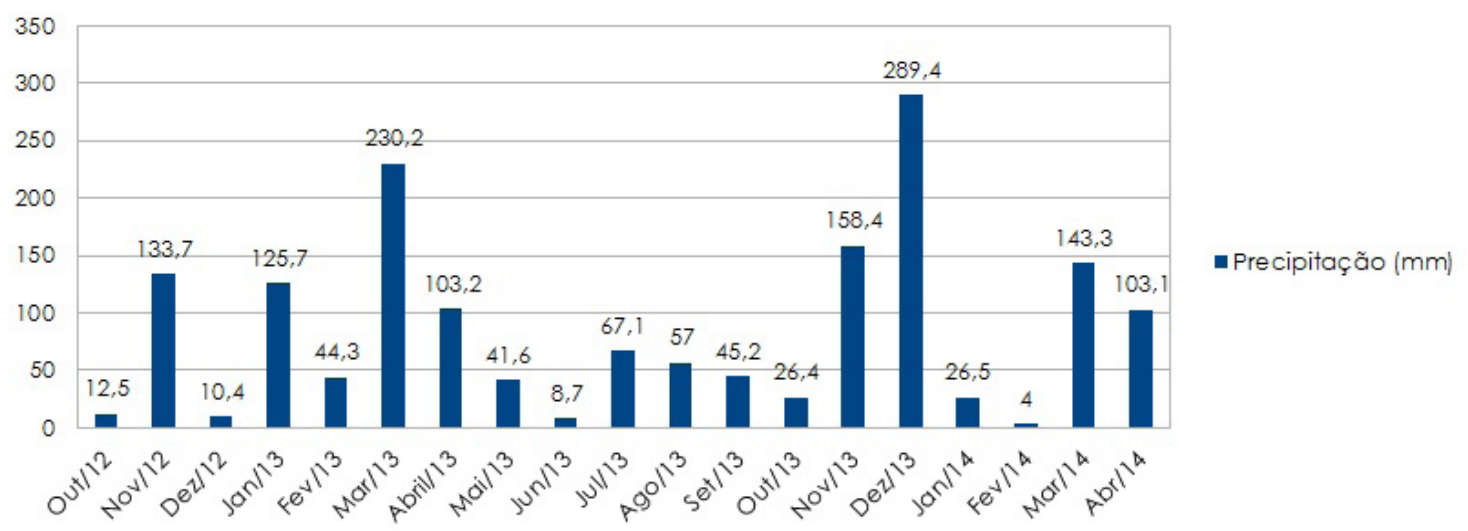

Figura 1. Precipitação pluvial (mm) durante o período de crescimento do capim-elefante no campo (Campos dos Goytacazes, RJ, 2012/2013/2014). Fonte: Estação Evapotranspirométrica do Centro Estadual de Pesquisa em Agroenergia e Aproveitamento de Resíduos, Campos dos Goytacazes, RJ.

Os genitores femininos foram escolhidos com base na época de florescimento (florescimento tardio) e em suas características morfoagronomicas (produção de massa seca, diâmetro do colmo, número de perfilhos) (Rossi, 2010). Já os genitores masculinos foram escolhidos com base na divergência genética em relação aos genitores femininos (Lima et al., 2011) e em suas características morfoagronômicas (produção de massa seca, diâmetro do colmo, número de perfilhos) (Rossi, 2010). Dentre estes acessos, foram designados dez genitores, sendo cinco genitores femininos (G1, G2, G3, G4 e G5) (grupo 1) e cinco genitores masculinos (G6, G7, G8, G9 e G10) (grupo 2) formando um dialelo parcial $5 \times 5$ (Tabela 1). Além dos genitores foi utilizada uma testemunha selecionada com base na alta produção de matéria seca e florescimento tardio (Rossi, 2010). Todas as combinações hibridas foram obtidas, permitindo 
a elaboração de esquema de cruzamento em dialelo parcial, segundo Cruz et al. (2012) (Tabela 1).

Após a multiplicação dos híbridos e preparo convencional do solo, foi realizado o plantio das estacas com três gemas obtidas de diferentes plantas. Essas estacas foram dispostas em pé com ponta, distribuídas em sulcos de 10 $\mathrm{cm}$ de profundidade. O plantio foi realizado em junho de 2012. Após a fase de estabelecimento, em outubro de 2012 (90 dias após plantio), todos os genótipos foram cortados rente ao solo (corte de uniformização). Foram realizados três cortes de avaliações no intervalo de seis em seis meses, sendo dois em abril (abril de 2013 e abril de 2014) referentes ao período de crescimento na estação chuvosa (de outubro a abril) e um corte referente ao período de crescimento na estação seca (realizado em outubro de 2013).

Tabela 1. Esquema de cruzamentos do dialelo parcial com dez genitores.

\begin{tabular}{cccccc}
\hline \multirow{2}{*}{ Genitores masculinos } & \multicolumn{5}{c}{ Genitores femininos } \\
\cline { 2 - 6 } & $\begin{array}{c}\text { Cubano } \\
\text { Pinda (G1) }\end{array}$ & $\begin{array}{c}\text { Cameroon- } \\
\text { Piracicaba (G2) }\end{array}$ & $\begin{array}{c}\text { P241- } \\
\text { Piracicaba (G3) }\end{array}$ & $\begin{array}{c}\text { IAC-Campinas } \\
\text { (G4) }\end{array}$ & $\begin{array}{c}\text { Guaçu/IZ.2 } \\
\text { (G5) }\end{array}$ \\
\hline Mercker (G6) & $\mathrm{H} 1$ & $\mathrm{H} 6$ & $\mathrm{H} 11$ & $\mathrm{H} 16$ & $\mathrm{H} 21$ \\
Três Rios (G7) & $\mathrm{H} 2$ & $\mathrm{H} 7$ & $\mathrm{H} 12$ & $\mathrm{H} 17$ & $\mathrm{H} 22$ \\
Mercker 86-México (G8) & $\mathrm{H} 3$ & $\mathrm{H} 8$ & $\mathrm{H} 13$ & $\mathrm{H} 18$ & $\mathrm{H} 23$ \\
Taiwan A-144 (G9) & $\mathrm{H} 4$ & $\mathrm{H} 9$ & $\mathrm{H} 14$ & $\mathrm{H} 19$ & $\mathrm{H} 24$ \\
Roxo (G10) & $\mathrm{H} 5$ & $\mathrm{H} 10$ & $\mathrm{H} 15$ & $\mathrm{H} 20$ & $\mathrm{H} 25$ \\
\hline
\end{tabular}

A adubação foi realizada no plantio com $100 \mathrm{~kg} \cdot \mathrm{ha}^{-1}$ de $\mathrm{P}_{2} \mathrm{O}_{5}$ (Super Fosfato Simples). Após o corte de uniformização foi realizada nova adubação de cobertura utilizando-se $25 \mathrm{~kg} \mathrm{ha}^{-1}$ de Sulfato de Amônio e $25 \mathrm{~kg} \cdot \mathrm{ha}^{-1}$ de Cloreto de potássio. As características morfoagronomicas avaliadas são descritas a seguir:

1. altura das plantas (ALT) - foram tomadas as medidas de três plantas de cada parcela ao acaso, obtida pela medição com régua graduada e expressa em metros;

2. diâmetro do colmo (DC) - utilizando-se um paquímetro digital, foram medidos os diâmetros do colmo de três plantas ao acaso de cada parcela a cerca de 20 $\mathrm{cm}$ do solo e os resultados expressos em centímetros;

3. largura da lâmina foliar (LL) - mensurada na parte central da primeira folha totalmente expandida de três plantas ao acaso de cada parcela e expressa em centímetros:

4. número de perfilhos por metro linear (NP) realizada através da contagem do número de perfilhos em 1,5 m linear na linha da parcela sendo, o resultado, foi convertido para número de perfilhos por metro linear. Foram pesados ainda na área experimental os perfilhos provenientes de 1,5 $\mathrm{m}$ de cada parcela. Após pesagem foram coletadas amostras de três perfilhos, estes passados em picadeira e embalados em sacos de papel. Os materiais (folhas e colmos) de cada parcela, pesados e devidamente identificados, foram secos em estufa de ventilação forcada, a $65^{\circ} \mathrm{C}$ por 72 horas. Em seguida as amostras foram novamente pesadas para obtenção da amostra seca ao ar (ASA), de acordo com a metodologia descrita por Silva e Queiroz (2002). material seco (folha e colmo) foi moído em moinho tipo Willey com peneira de $1 \mathrm{~mm}$ e acondicionado em sacos plásticos para a determinação da amostra seca em estuda (ASE). Para a determinação da ASE, dois gramas de cada material moído foram mantidos em estufa a $105^{\circ} \mathrm{C}$ por $12 \mathrm{~h} \mathrm{e}$, posteriormente, novamente pesados.

5. porcentagem de massa seca (\%MS) obtida pela multiplicação dos valores da amostra seca ao ar e amostra seca em estufa;

6. produção de matéria seca (PMS) estimada a partir da porcentagem de matéria seca e do peso de perfilhos em 1,5 $m$ de cada parcela. Os resultados obtidos foram transformados para que fossem expressos em t.ha-1

O delineamento utilizado foi de blocos 
casualizados, com três repetições. A unidade experimental foi composta por uma linha de seis metros espaçada de 1,5 m entre linhas, sendo consideradas úteis apenas $1,5 \mathrm{~m}$ dentro das linhas, desprezando-se as extremidades.

Em cada corte de avaliação foi realizada uma análise de variância com base na média das parcelas para cada uma das características avaliadas descritas anteriormente, considerandose como fixos todos os efeitos, exceto bloco e erro experimental (modelo fixo).

As médias dos tratamentos em cada estação (chuvosa e seca) foram agrupadas pelo critério de média Scott-Knott a $5 \%$ de probabilidade. Após análise de variância individual para cada corte de avaliação $(6,12$ e 18 meses após os corte de uniformização) foi verificada a homogeneidade das variâncias residuais. Em seguida foi realizada a análise de variância conjunta em parcelas subdivididas no tempo onde o tratamento principal foram os 36 genótipos (25 híbridos, 10 genitores e 1 testemunha) e os tratamentos nas subparcelas foram os cortes de avaliações.

Para a determinação das estimativas estatísticas utilizou-se o aplicativo computacional em genética e estatística, programa Genes (Cruz, 2013).

\section{Resultados e Discussão}

Análise de variância

Pôde-se verificar que no primeiro corte da estação chuvosa houve significância $(P<0,01)$ entre genótipos para a característica altura da planta (ALT), porém não houve diferenças significativas entre a testemunha e os demais genótipos avaliados (genitores e híbridos). O mesmo ocorrev entre genitores e híbridos. Apenas para o contraste entre genitores femininos e masculinos foi encontrada significância $(P<0,01)$ pelo teste F. A média geral nesse corte foi de 2,26 m (Tabela 2). Souza Sobrinho et al. (2005) avaliando híbridos entre genótipos de capimelefante e milheto, em dialelo parcial, aos 72 , $73,66,92,97,65,67$ e 81 dias de crescimento encontraram média geral para altura de planta de 1,76 m com híbridos apresentando até 1,99 m, ou seja, valor próximo ao observado no presente trabalho com o corte de avaliação realizado aos 6 meses de crescimento.

Mesmo apresentando coeficiente de variação considerado baixo (8,86\%), não houve diferenças significativas para a característica diâmetro do colmo (DC) no primeiro corte da estação chuvosa. $\bigcirc$ valor médio observado de 1,43 cm (Tabela 2) para essa característica foi similar aos encontrados por Ferreira et al. (2013) nos genótipos Roxo de Botucatu $(1,44 \mathrm{~cm})$ e Cuba-1 16-29.3 (1,48cm) na região semi-árida de Pernambuco.

Em relação à característica largura da lâmina foliar (LL) no primeiro corte da estação chuvosa houve diferenças significativas entre os genótipos avaliados em nível de $1 \%$ de probabilidade. $O$ único contraste em que não foram observadas diferenças significativas foi entre genitores e híbridos os quais apresentaram média geral de 4,33 e 4,35 cm, respectivamente. Em relação à testemunha e aos demais genótipos as diferenças ocorreram a $5 \%$ de probabilidade (Tabela 2).

O número de perfilhos por metro linear (NP) apresentou significância entre os genótipos a $1 \%$ de probabilidade. Em relação ao contraste testemunha e os demais genótipos (genitores e híbridos) observou-se efeito significativo $(P<0,05)$ pelo teste F. Pôde-se observar que a testemunha obteve média de 25 perfilhos por metro linear enquanto que as médias dos genitores e híbridos foram de 31 e 34 perfilhos, respectivamente (Tabela 2). Na análise da característica DC, foi constatado que a testemunha obteve valor menor comparando com as médias gerais de DC dos genitores e híbridos. Isso porque geralmente o maior DC está correlacionado a menor produção de perfilhos (Daher et al., 2004).

As diferenças significativas em nível de $1 \%$ de probabilidade para a característica porcentagem de matéria seca (\%MS) no primeiro corte de avaliação da estação chuvosa ocorreu apenas entre genótipos de forma geral. Resultado semelhante foi observado para a característica produção de matéria seca (PMS), com exceção da significância a $1 \%$ de probabilidade entre genitores e híbridos (Tabela 2). 
Tabela 2. Estimativas dos quadrados médios, das médias e coeficiente de variação de seis características morfoagronômicas avaliadas em genótipos de capim-elefante no primeiro corte da estação chuvosa.

\begin{tabular}{|c|c|c|c|c|c|c|}
\hline \multirow{2}{*}{ Quadrado médio } & \multicolumn{6}{|c|}{ Características"/ } \\
\hline & ALT & DC & LL & NP & $\% M S$ & PMS \\
\hline Bloco & 0,1951 & 0,0279 & 1,4531 & 0,3478 & 23,2915 & 26,8927 \\
\hline Genótipos & $0,1013^{* *}$ & $0,0199^{\text {ns }}$ & $0,2671^{* *}$ & $138,5371^{* *}$ & $15,6629 * *$ & $36,2612^{* *}$ \\
\hline $\begin{array}{l}\text { Testemunha vs genitores e } \\
\text { híbridos }\end{array}$ & $0,0553^{\text {ns }}$ & $0,0603^{\text {ns }}$ & $0,7896^{*}$ & $185,6015^{*}$ & $12,7962^{\text {ns }}$ & $21,7807^{\text {ns }}$ \\
\hline Genitores vs híbridos & $0,0063^{\text {ns }}$ & $0,0022^{\text {ns }}$ & $0,1449^{\text {ns }}$ & $175,4406^{*}$ & $9,5320^{\text {ns }}$ & $295,6653^{* *}$ \\
\hline $\begin{array}{l}\text { Genitores masculinos vs } \\
\text { genitores femininos }\end{array}$ & $0,6551^{* *}$ & $0,0051^{\mathrm{ns}}$ & $1,3511^{* *}$ & $235,2000^{*}$ & $8,8530^{\text {ns }}$ & $20,0072^{\text {ns }}$ \\
\hline Resíduo & 0,0322 & 0,0160 & 0,1275 & 36,5687 & 6,9633 & 17,9301 \\
\hline Média geral & 2,26 & 1,43 & 4,36 & 33 & 24,86 & 19,62 \\
\hline Média testemunha & 2,39 & 1,57 & 4,87 & 25 & 26,90 & 22,28 \\
\hline Média geral dos genitores & 2,24 & 1,42 & 4,33 & 31 & 24,33 & 16,09 \\
\hline Média geral dos híbridos & 2,26 & 1,45 & 4,35 & 34 & 24,99 & 20,61 \\
\hline CV (\%) & 7,95 & 8,86 & 8,19 & 32,75 & 10,61 & 21,58 \\
\hline
\end{tabular}

Resultados contrastantes foram obtidos no corte da estação seca em relação ao primeiro corte estação chuvosa. Não houve diferenças significativas na ALT entre genitores masculinos e femininos, mas houve diferenças entre genitores e híbridos a $5 \%$ de probabilidade. O mesmo ocorreu na comparação entre a testemunha e os demais genótipos, sendo possível obter diferenças significativas para esse contraste em nível de $5 \%$ de probabilidade (Tabela 3).

No corte da estação seca foi detectada diferenças entre os genótipos a $1 \%$ de probabilidade para a característica DC. Ao analisar cada contraste efetuado isoladamente pode-se observar diferenças significativas apenas entre genitores e híbridos também a $1 \%$ de probabilidade. A média geral de $1,46 \mathrm{~cm}$ para a característica DC (Tabela 3) foi similar ao encontrado no primeiro corte da estação chuvosa $(1,43 \mathrm{~cm})$.

Houve diferença estatística entre os genitores masculinos e femininos para a característica LL não sendo detectadas diferenças entre genitores e híbridos (Tabela 3). Silva et al. (2010), ao avaliarem caracteres morfológicos em clones de capim-elefante em três cortes aos 60 dias de crescimento observaram valor médio geral para a característica LL de $3,16 \mathrm{~cm}$. No presente estudo no corte da seca realizado aos 6 meses de crescimento o valor médio geral foi de $3,59 \mathrm{~cm}$, ou seja, os acréscimos nessa característica a partir de certo estádio de desenvolvimento da planta não são significativos.

A característica NP no corte da estação seca não apresentou significância pelo teste $F$ entre os grupos de genitores femininos $e$ masculinos, ao contrário do primeiro corte da estação chuvosa. Os resultados também mostram que existem diferenças na produção de perfilhos entre genitores e híbridos. Isso pode ser observado pela media geral destes grupos de genótipos. A média geral da característica NP dos híbridos foi de 32 perfilhos enquanto que a dos genitores foi de 28 perfilhos por metro linear (Tabela 3).

O capim-elefante vem sendo avaliado com a finalidade energética devido a alta capacidade de produção de biomassa (Morais et al., 2011). Visando a obtenção de híbridos com capacidade de produção de biomassa superior aos seus genitores pode-se observar que em relação à \%MS não houve diferenças significativas entre genitores e híbridos. No caso da característica PMS houve efeito significativo $(P<0,05)$ entre genitores e híbridos pelo teste F, com médias gerais de 5,43 e 6,65 t.ha ${ }^{-1}$, respectivamente (Tabela 3), denotando a 
expressão do vigor híbrido para este grupo de genótipos avaliados, em concordância com Bernini \& Paterniani (2012) que evidenciaram potencial heterótico de híbridos de populações $\mathrm{F}_{2}$ de milho em cruzamentos dialélicos, utilizando a metodologia de Gardner \& Eberhart (1966).

Tabela 3. Estimativas dos quadrados médios, das médias e coeficiente de variação de seis características morfoagronômicas avaliadas em genótipos de capim-elefante no corte da estação seca.

\begin{tabular}{|c|c|c|c|c|c|c|}
\hline \multirow{2}{*}{ Quadrado médio } & \multicolumn{6}{|c|}{ Características"/ } \\
\hline & ALT & $D C$ & $\mathrm{LL}$ & NP & $\% M S$ & PMS \\
\hline Bloco & 0,1393 & 0,0630 & 0,0210 & 1,1956 & 65,7644 & 1,1369 \\
\hline Genótipos & $0,1022 *$ & $0,1764^{* *}$ & $1,1121^{* *}$ & $205,151^{* *}$ & $50,1125^{*}$ & $12,3070^{*}$ \\
\hline $\begin{array}{l}\text { Testemunha vs genitores e } \\
\text { híbridos }\end{array}$ & $0,6082^{* *}$ & $0,2222^{\text {ns }}$ & $0,5071^{\mathrm{ns}}$ & $353,9563^{*}$ & $128,3770^{*}$ & $12,5706^{\mathrm{ns}}$ \\
\hline Genitores vs híbridos & $0,2801^{*}$ & $0,5875^{* *}$ & $0,8792^{\text {ns }}$ & $336,2606^{*}$ & $7,2513^{\text {ns }}$ & $28,7277^{*}$ \\
\hline $\begin{array}{l}\text { Genitores masculinos vs } \\
\text { genitores femininos }\end{array}$ & $0,0067^{\mathrm{ns}}$ & $0,0000^{\text {ns }}$ & $6,9601^{* *}$ & $1,5413^{\text {ns }}$ & $183,9753^{*}$ & $20,5279^{\text {ns }}$ \\
\hline Resíduo & 0,0581 & 0,0787 & 0,2300 & 76,5647 & 27,0388 & 6,7303 \\
\hline Média geral & 1,86 & 1,46 & 3,59 & 30 & 20,88 & 6,36 \\
\hline Média testemunha & 2,30 & 1,56 & 4,00 & 20 & 27,34 & 8,38 \\
\hline Média geral dos genitores & 1,75 & 1,34 & 3,43 & 28 & 20,93 & 5,43 \\
\hline Média geral dos híbridos & 1,88 & 1,50 & 3,64 & 32 & 20,87 & 6,65 \\
\hline CV (\%) & 12,99 & 19,19 & 13,34 & 28,96 & 24,90 & 40,80 \\
\hline
\end{tabular}

Em relação ao segundo corte da estação chuvosa as características ALT e DC apresentaram significância em nível de 1\% de probabilidade pelo teste $F$, no entanto não ocorreram diferenças entre os contrastes realizados (testemunha vs genitores e híbridos, genitores vs híbridos, genitores femininos vs genitores masculinos) (Tabela 4). Carneiro et al. (2006) ao avaliarem o consórcio de capimelefante com leucena observaram que a altura da planta é influenciada pela densidade de plantio, onde as maiores alturas de planta $(2,01$ m) ocorreram no espaçamento de 1,0 m entre linhas.

Apenas no contraste entre genitores masculinos e femininos para a característica LL não foram observadas diferenças significativas pelo teste F. Ao comparar testemunha e os demais genótipos é possível detectar diferenças significativas a $1 \%$ de probabilidade. A testemunha apresentou média para a característica largura de folha de $4,15 \mathrm{~cm}$, enquanto que genitores e híbridos apresentaram médias gerais inferiores, com valores de 3,51 e $3,48 \mathrm{~cm}$, respectivamente (Tabela 4). Segundo Price \& Casler (2014) a seleção direta para produção de biomassa em Poaceae tem sido difícil devido a muitos fatores. A identificação de características morfológicas associadas com a produção de matéria seca pode aumentar a eficiência do melhoramento genético dessas espécies.

Em relação às características NP, \%MS e PMS observou-se efeito significativo $(P<0,01)$ entre os genótipos, mas não ocorreram diferenças significativas para os contrastes utilizados no presente estudo (Tabela 4), diferentemente do que ocorreu nos primeiros cortes da estação chuvosa e seca. Segundo Silva et al. (2010), avaliando genótipos na Zona da Mata de Pernambuco, é possível obter ganhos genéticos em capim-elefante para maior produção de biomassa selecionando indiretamente genótipos com maior produção de perfilhos. Segundo Cunha et al. (2011) a produção de perfilhos está correlacionada positivamente com a PMS, ou seja, quanto maior a produção de perfilhos maior também será a produção de biomassa em capim-elefante.

Ao verificar a análise de variância conjunta observou-se que houve efeito significativo a $1 \%$ de probabilidade para os genótipos em todas as características avaliadas (Tabelas 5). Esse resultado indica a presença de variabilidade genética devido ao cruzamento de genitores altamente heterozigóticos e que pode ser explorada pela seleção em programas de melhoramento de plantas (Cavalcante et 
al., 2013). Para o efeito de corte (ambiente) na subparcela apenas a variável DC não apresentou significância pelo teste de $\mathrm{F}$ de
Fisher. A variável \%MS apresentou significância, mas em nível de $5 \%$ (Tabelas 5).

Tabela 4. Estimativas dos quadrados médios, das médias e coeficiente de variação de seis características morfoagronômicas avaliadas em genótipos de capim-elefante no segundo corte da estação chuvosa.

\begin{tabular}{|c|c|c|c|c|c|c|}
\hline \multirow{2}{*}{ Quadrado médio } & \multicolumn{6}{|c|}{ Características"/ } \\
\hline & ALT & $\mathrm{DC}$ & $\mathrm{LL}$ & NP & $\% \mathrm{MS}$ & PMS \\
\hline Bloco & 0,0654 & 0,1456 & 0,4001 & 25,7203 & 9,5207 & 0,9420 \\
\hline Genótipos & $0,1264^{* *}$ & $0,0602^{* *}$ & $0,3678^{* *}$ & $215,3376^{* *}$ & $14,8474^{* *}$ & $44,3619^{* *}$ \\
\hline $\begin{array}{l}\text { Testemunha vs genitores e } \\
\text { híbridos }\end{array}$ & $0,2058^{\text {ns }}$ & $0,0049^{\text {ns }}$ & $1,2797^{* *}$ & $138,8625^{\text {ns }}$ & $3,8455^{\mathrm{ns}}$ & $74,7967^{\text {ns }}$ \\
\hline Genitores vs híbridos & $0,0681^{\mathrm{ns}}$ & $0,0005^{\text {ns }}$ & $0,0440^{\text {ns }}$ & $39,5178^{\mathrm{ns}}$ & $0,1584^{\text {ns }}$ & $75,7807^{\mathrm{ns}}$ \\
\hline $\begin{array}{l}\text { Genitores masculinos vs } \\
\text { genitores femininos }\end{array}$ & $0,0370^{\text {ns }}$ & $0,0024^{\mathrm{ns}}$ & $1,7280^{*}$ & $122,0083^{\text {ns }}$ & $1,6375^{\mathrm{ns}}$ & $33,4222^{\text {ns }}$ \\
\hline Resíduo & 0,0642 & 0,0294 & 0,0854 & 76,5055 & 6,7875 & 23,0439 \\
\hline Média geral & 2,16 & 1,52 & 3,51 & 35 & 23,83 & 14,67 \\
\hline Média testemunha & 1,90 & 1,48 & 4,15 & 28 & 24,95 & 9,74 \\
\hline Média geral dos genitores & 2,10 & 1,52 & 3,51 & 34 & 23,74 & 13,46 \\
\hline Média geral dos híbridos & 2,20 & 1,52 & 3,48 & 36 & 23,83 & 15,35 \\
\hline CV (\%) & 11,74 & 11,31 & 8,34 & 24,96 & 10,93 & 32,73 \\
\hline
\end{tabular}

Tabela 5. Estimativas dos quadrados médios, das médias e coeficiente de variação da análise conjunta dos três cortes e seis características morfoagronômicas avaliadas em genótipos de capim-elefante.

\begin{tabular}{|c|c|c|c|c|c|c|}
\hline \multirow{2}{*}{ Quadrado médio } & \multicolumn{6}{|c|}{ Características"/ } \\
\hline & ALT & $\mathrm{DC}$ & $\mathrm{LL}$ & $\mathrm{NP}$ & $\% M S$ & PMS \\
\hline Bloco & 0,2391 & 0,0780 & 1,1579 & 7,7746 & 8,1845 & 9,3196 \\
\hline Genótipo (G) & $0,1556^{* *}$ & $0,0853^{* *}$ & $1,2123^{* *}$ & $382,6802 * *$ & $33,8710^{* *}$ & $52,5976 * *$ \\
\hline Erro a & 0,0615 & 0,0415 & 0,1649 & 91,6428 & 13,3468 & 20,4477 \\
\hline Corte (C) & $4,7195^{* *}$ & $0,2274^{\mathrm{ns}}$ & $23,8311^{* *}$ & $630,8717^{* *}$ & $460,2612^{*}$ & $4852,4654^{* *}$ \\
\hline Erro b & 0,0804 & 0,0793 & 0,3581 & 9,7445 & 45,1961 & 9,8260 \\
\hline Interação (GvsC) & $0,0871^{* *}$ & $0,0856^{* *}$ & $0,2674^{* *}$ & $88,1726^{* *}$ & $23,375894^{* *}$ & $20,1662^{*}$ \\
\hline Erro C & 0,0465 & 0,0413 & 0,1390 & 48,9980 & 13,7214 & 13,6283 \\
\hline Média & 2,09 & 1,47 & 3,82 & 17 & 23,19 & 13,55 \\
\hline CVa (\%) & 11,86 & 13,86 & 10,63 & 29,30 & 15,75 & 33,37 \\
\hline CVb (\%) & 13,56 & 19,17 & 15,67 & 9,55 & 28,98 & 23,13 \\
\hline$C V_{C}(\%)$ & 10,31 & 13,84 & 9,76 & 21,43 & 15,97 & 27,24 \\
\hline
\end{tabular}

Considerando que os cortes de avaliação representam o fator ambiental, houve interação significativa entre genótipos e ambientes para todas as características avaliadas (Tabelas 5). Os genótipos responderam diferentemente as diferentes variações ambientais com alterações no posicionamento do genótipo ou mudanças na magnitude das diferenças entre genótipos de ambiente para outro (Silva, 2008). A interação genótipo vs ambiente é de grande importância para o melhoramento de plantas, mas dificulta a identificação de genótipos superiores para diferentes ambientes (Faria et al. 2009).

Além da análise de variância individual e conjunta dos cortes de avaliação, foi realizada também a análise de variância da média da PMS na estação chuvosa, dos três cortes, do total do primeiro ano de avaliação, da porcentagem de contribuição da PMS da estação seca na produção do primeiro ano e da PMS na estação seca (já apresentada anteriormente) e encontram-se na Tabela 6.

Primeiramente pode-se verificar que não houve, para os níveis de probabilidade testados, apenas para a porcentagem de contribuição da PMS da estação seca na produção do primeiro ano, ou seja, os genótipos não diferiram quando a PMS na estação seca em relação à produção total. A média geral da PMS no primeiro ano de avaliação foi de 25,98 t.ha-1 (Tabela 6) que está 
abaixo do potencial de produção massa seca do capim-elefante que é de 30 a 45 t.ha ${ }^{-1}$.ano-1 (Gomes et al., 2013).

A média de PMS na estação chuvosa foi de 17,14 t.ha ${ }^{-1}$ enquanto na seca foi de 6,36 t. ha $^{-1}$ (Tabela 6). A menor produtividade observada no corte dessa estação foi devido à menor precipitação ocorrida durante o período de crescimento da planta. Durante o primeiro e segundo corte da estação chuvosa a precipitação total foi de 556 e $648 \mathrm{~mm}$, respectivamente, enquanto na seca foram contabilizados $322,8 \mathrm{~mm}$ (Figura 1). Segundo Teixeira Vitor et al. (2009) a baixa intensidade luminosa associada a temperaturas inferiores a $15^{\circ} \mathrm{C}$ que ocorrem na estação seca podem limitar a produção em genótipos de capimelefante, o que também explica a baixa PMS nessa estação no presente estudo.

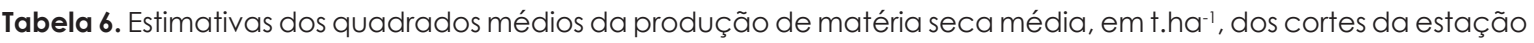
chuvosa (Chuvosa), no corte da estação seca (Seca), médias dos três cortes (3 cortes), média do primeiro ano ( $1^{\circ} \mathrm{ano}$ ) e porcentagem na produção de matéria seca no corte da seca (\%Seca) em relação a produção do primeiro ano.

\begin{tabular}{llllll}
\hline \multirow{2}{*}{ Quadrado médio } & \multicolumn{5}{c}{ Produção de matéria seca } \\
\cline { 2 - 6 } & \multicolumn{1}{c}{ Chuvosa } & \multicolumn{1}{c}{ Seca } & \multicolumn{1}{c}{3 cortes } & $1^{\circ}$ ano & \%Seca \\
\hline Bloco & 4,4461 & 1,1369 & 3,0996 & 39,0611 & 13,1727 \\
Genótipos & $27,4784^{* *}$ & $12,3070^{*}$ & $17,5372^{* *}$ & $68,9381^{* *}$ & $92,1348^{\text {ns }}$ \\
Resíduo & 10,9632 & 6,7303 & 6,8167 & 29,4354 & 64,2057 \\
\hline Média geral & 17,14 & 6,36 & 13,55 & 25,98 & 24,09 \\
CV (\%)" & 19,31 & 40,80 & 19,27 & 20,88 & 33,26 \\
\hline "CV - coeficiente de variação. **significativo a 1\% de probabilidade; *significativo a 5\% de probabilidade; "nño significativo a 5\% de probabilidade \\
pelo teste F.
\end{tabular}

\section{Agrupamento de médias}

Com relação aos cortes da estação chuvosa optou-se pela realização do agrupamento pelo teste de Scott-Knott com a média do primeiro e segundo cortes (Tabela 7). Isso porque ao realizar a análise de variância conjunta entre os dois cortes de avaliação não houve diferenças significativas $(P>0,05)$ para a interação na maioria das características. A interação genótipo vs ambiente (corte) apenas apresentou significância $(P<0,01)$ na característica NP.

A característica ALT nos cortes de avaliação da estação chuvosa separou os genótipos em dois grupos. Apenas os genitores masculinos G6 (Mercker) e G9 (Taiwan A-144) estiveram entre os doze genótipos classificados com maiores ALT. Os valores das alturas desses dois genótipos foram 2,41 e 2,52 m. O híbrido com maior valor $(2,60 \mathrm{~m})$ de altura encontrado entre os genótipos agrupados como de maiores ALT foi o H18 (IAC-Campinas x Mercker 86-México) (Tabela 7). A obtenção de híbridos com maiores ALT é aspecto favorável quando se deseja selecionar materiais genéticos de capimelefante para a produção de energia, pois a
ALT é correlacionada positivamente com PMS (Zhang et al. 2010).

Já em relação ao corte de avaliação da estação seca observa-se que o híbrido H18 esteve no grupo de menor ALT com valor de 1,62 m. Resultado semelhante foi observado para a testemunha (Capim Cana D' África) em que apresentou-se entre os genótipos de maiores alturas, com valor de 2,14 m, e entre os de menores ALT nos cortes da estação chuvosa, com valor de $2,30 \mathrm{~m}$. Isso ocorreu devido a interação genótipo vs ambiente (corte) significativa $(P<0,05)$ (Tabela 8).

No caso das características NP e DC nos cortes de avaliação da estação chuvosa e seca observa-se a separação dos genótipos em dois grupos. Os híbridos H3 (Cubano Pinda x Mercker 86-México) e H21 (Guaçu/IZ.2 x Mercker) e a testemunha (Capim Cana D' África) foram reunidos no grupo de maiores DC e menores NP. Os valores de DC desses genótipos nos cortes da estação chuvosa foram de 1,59; 1,61 e 1,52 $\mathrm{cm}$ e no corte da seca de 1,57; 1,61 e 1,73 cm, respectivamente. A característica NP desses genótipos nos cortes da estação chuvosa foram de 26, 31 e 27 e no corte da seca de 29, 28 e 
19 (Tabelas 7 e 8). Esses resultados estão de acordo com Daher et al. (2004) que observaram correlação negativa entre as características DC e NP em genótipos de capim-elefante.

Nos cortes de avaliação da estação chuvosa os genótipos foram separados em quatro grupos segundo o teste de Scott-Knott $(P<0,05)$ no caso da característica LL. No grupo com maiores LL não foi encontrado nenhum dos híbridos, apenas com genitores Gl (Cubano Pinda), G2 (Cameroon - Piracicaba) e G5 (Guaçu/ IZ.2) e a testemunha (Capim Cana D' África) com valores de 4,54; 4,47; 4,36; e 4,51, respectivamente (Tabela 7). Porém, no corte da estação seca os híbridos H13 (P241-Piracicaba x Mercker 86-México) e H25 (Guaçu/IZ.2 x Roxo) foram que apresentaram maiores $L L$ de 5,01 e $4,89 \mathrm{~cm}$ (Tabela 8). Quanto mais curto o intervalo entre cortes maior é a proporção de folhas no material colhido. No caso da alimentação animal isso é desejável devido ao maior teor de proteína. Em relação ao material destinado a produção de energia a estratégia deve ser contrária, pois o baixo teor de proteína promove a produção de calor de forma mais eficiente (Morais et al. 2009).

Os genótipos de capim-elefante foram classificados em dois grupos na característica PMS nos cortes da estação chuvosa pelo teste de Scott-Knott $(P<0,05)$ (Tabela 8). Apenas dois genitores apresentaram-se no grupo com maiores produções. Esses genitores foram o G6 (Mercker) com valor de 19,76 e o G9 (Taiwan A-144) com valor de 18,57. Com isso constata-se que foi possível obter híbridos de desempenho superior a de seus genitores. Contudo, Flores et al. (2012) em avaliação de genótipos de capim-elefante, com corte efetuado aos seis meses de crescimento e em condições de

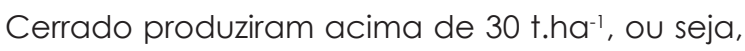
rendimentos superiores ao do presente estudo.

Já em relação ao corte da estação seca não houve separação dos genótipos em grupos distintos para a característica PMS pelo teste de Scott-Knott, mas observa-se que no caso do teste Tukey a $5 \%$ de probabilidade, com DMS de 8,49, diferenças seriam detectadas entre o genitor masculino G8 (Mercker 86-México) e o híbrido H8 (Cameroon - Piracicaba x Mercker
86-México) que correspondem às produções de 2,10 e 11,24 t.ha- ${ }^{-1}$, respectivamente (Tabela 8).

Com objetivo de se selecionar híbridos com maiores produções de biomassa verificouse as combinações híbridas H4 (Cubano Pinda $x$ Taiwan A-144), H7 (Cameroon - Piracicaba $x$ Três Rios), H8 (Cameroon - Piracicaba x Mercker 86-México), H1O (Cameroon-Piracicaba x Roxo), H13 (P241-Piracicaba x Mercker 86-México), H17 (IAC-Campinas $x$ Três Rios) e H18 (IAC-Campinas $x$ Mercker 86-México) apresentaram-se no grupo com maior PMS nos cortes da estação chuvosa. Os valores de PMS desses híbridos nesse corte foram de 20,76; 20,36; 20,67; 17,98; 18,52; 20,16 e 22,96 t.ha-1, respectivamente. Estas mesmas combinações híbridas estiveram entre os $36 \%$ primeiros genótipos com maiores valores de PMS no corte da seca, ou seja, esses híbridos mantiveram-se entre os mais produtivos no corte da estação chuvosa e seca, mesmo com produção mais baixa no corte da seca em relação aos cortes da estação chuvosa. Os valores de PMS dessas combinações híbridas no corte da estação seca foram de 6,99; 10,32; 11,$23 ; 8,2 ; 7,6 ; 9,71$ e 7,22 t.ha $^{-1}$, respectivamente.

\section{Conclusão}

Foi possível a obtenção de híbridos com desempenho produtivo superior a de seus genitores.

De acordo com a avaliação per se do genótipos, deve-se selecionar híbridos $\mathrm{H} 4$ (Cubano Pinda x Taiwan A-144), H7 (Cameroon - Piracicaba x Três Rios), H8 (Cameroon Piracicaba xMercker 86-México), H10 (Cameroon - Piracicaba x Roxo), H13 (P241-Piracicaba x Mercker 86-México), H17 (IAC-Campinas x Três Rios) e H18 (IAC-Campinas x Mercker 86-México) quando o objetivo for obter maiores produções de biomassa tanto na estação chuvosa quanto na seca.

\section{Agradecimentos}

A Fundação de Amparo à Pesquisa do Estado do Rio de Janeiro pelo apoio financeiro. 
Tabela 7. Altura da planta (ALT - m), diâmetro do colmo (DC - cm), largura da lâmina foliar (LL - cm), número de perfilhos por metro linear, percentagem de matéria seca (\%MS) e produção de matéria seca em genótipos (PMS - t.ha-1) de capim-elefante na estação chuvosa (Campos dos Goytacazes, RJ, 2013/2014).

\begin{tabular}{|c|c|c|c|c|c|c|c|c|c|c|c|c|}
\hline \multirow{3}{*}{$\begin{array}{ll} & \begin{array}{c}\text { Genó- } \\
\text { tipos }\end{array} \\
\mathrm{Hl} & \end{array}$} & \multicolumn{12}{|c|}{ Características" } \\
\hline & \multicolumn{2}{|c|}{$\begin{array}{l}\text { ALT } \\
(\mathrm{m})\end{array}$} & \multicolumn{2}{|c|}{$\begin{array}{c}\mathrm{DC} \\
(\mathrm{cm})\end{array}$} & \multicolumn{2}{|c|}{$\begin{array}{c}\mathrm{LL} \\
(\mathrm{cm})\end{array}$} & \multicolumn{2}{|r|}{ NP } & \multicolumn{2}{|c|}{$\begin{array}{c}\% M S \\
(\%)\end{array}$} & \multicolumn{2}{|c|}{ PMS } \\
\hline & 2,30 & $a$ & 1,43 & $\mathrm{~b}$ & 4,24 & $b$ & 33 & $a$ & 26,98 & $a$ & 22,96 & $a$ \\
\hline $\mathrm{H} 2$ & 1,75 & $b$ & 1,61 & $a$ & 4,16 & $\mathrm{~b}$ & 24 & b & 23,87 & b & 10,45 & $b$ \\
\hline H3 & 2,39 & $a$ & 1,59 & $a$ & 3,86 & $c$ & 26 & $\mathrm{~b}$ & 27,60 & $a$ & 21,07 & $a$ \\
\hline $\mathrm{H} 4$ & 2,37 & $a$ & 1,47 & $b$ & 3,70 & $c$ & 38 & $a$ & 28,22 & $a$ & 20,76 & $a$ \\
\hline H5 & 2,16 & $b$ & 1,35 & $\mathrm{~b}$ & 4,09 & $\mathrm{~b}$ & 27 & $\mathrm{~b}$ & 19,98 & $b$ & 14,48 & $b$ \\
\hline H6 & 2,09 & $b$ & 1,41 & $b$ & 4,13 & $b$ & 35 & a & 25,75 & $a$ & 19,46 & $a$ \\
\hline $\mathrm{H} 7$ & 2,12 & $b$ & 1,50 & $a$ & 3,71 & $c$ & 50 & $a$ & 22,64 & $b$ & 20,36 & a \\
\hline H8 & 2,03 & $b$ & 1,60 & $a$ & 3,76 & $c$ & 38 & $a$ & 22,97 & $b$ & 20,67 & a \\
\hline H9 & 2,36 & $a$ & 1,61 & $a$ & 3,94 & $b$ & 35 & $a$ & 23,90 & $b$ & 16,78 & $b$ \\
\hline $\mathrm{H} 10$ & 2,14 & $b$ & 1,39 & $b$ & 3,95 & $b$ & 33 & $a$ & 23,32 & $b$ & 17,98 & a \\
\hline $\mathrm{HIl}$ & 2,09 & $b$ & 1,46 & $b$ & 3,70 & $c$ & 34 & $a$ & 24,10 & $b$ & 14,29 & $b$ \\
\hline $\mathrm{H} 12$ & 2,01 & $b$ & 1,36 & $b$ & 3,79 & $c$ & 43 & a & 23,34 & $b$ & 16,57 & $b$ \\
\hline $\mathrm{H} 13$ & 2,28 & $a$ & 1,48 & $\mathrm{~b}$ & 4,02 & $b$ & 36 & a & 22,01 & $b$ & 18,52 & a \\
\hline $\mathrm{H} 14$ & 2,32 & $a$ & 1,36 & $\mathrm{~b}$ & 4,00 & $\mathrm{~b}$ & 41 & $a$ & 24,15 & $b$ & 18,14 & $a$ \\
\hline $\mathrm{H} 15$ & 2,17 & $b$ & 1,33 & $b$ & 4,21 & $b$ & 33 & a & 22,88 & $b$ & 17,70 & a \\
\hline $\mathrm{H} 16$ & 2,34 & $a$ & 1,46 & $\mathrm{~b}$ & 4,04 & $b$ & 30 & b & 26,94 & a & 18,66 & a \\
\hline $\mathrm{H} 17$ & 2,48 & $a$ & 1,52 & $a$ & 3,88 & $c$ & 42 & $a$ & 25,47 & $a$ & 20,16 & $a$ \\
\hline $\mathrm{H} 18$ & 2,60 & $a$ & 1,44 & $b$ & 3,76 & $c$ & 36 & a & 25,21 & a & 22,96 & a \\
\hline $\mathrm{H} 19$ & 2,14 & $b$ & 1,45 & $\mathrm{~b}$ & 3,85 & $c$ & 36 & a & 27,35 & a & 19,31 & a \\
\hline $\mathrm{H} 2 \mathrm{O}$ & 2,18 & $b$ & 1,52 & $a$ & 4,04 & $b$ & 24 & b & 26,04 & $a$ & 16,06 & $b$ \\
\hline H21 & 2,24 & $b$ & 1,50 & $a$ & 4,10 & $b$ & 31 & b & 25,53 & a & 16,63 & $b$ \\
\hline $\mathrm{H} 22$ & 2,18 & $b$ & 1,58 & $a$ & 3,73 & $c$ & 42 & a & 22,86 & $b$ & 15,05 & $b$ \\
\hline $\mathrm{H} 23$ & 2,21 & $b$ & 1,54 & $a$ & 3,41 & $d$ & 30 & b & 22,55 & $b$ & 14,59 & $b$ \\
\hline $\mathrm{H} 24$ & 2,10 & $b$ & 1,41 & $b$ & 3,62 & d & 34 & a & 24,39 & $b$ & 16,37 & $b$ \\
\hline $\mathrm{H} 25$ & 2,37 & a & 1,49 & $a$ & 4,08 & $b$ & 34 & a & 22,17 & $b$ & 19,36 & a \\
\hline G1 & 2,15 & $b$ & 1,64 & $a$ & 4,54 & $a$ & 28 & $b$ & 25,36 & $a$ & 16,31 & $b$ \\
\hline G2 & 2,17 & $b$ & 1,56 & $a$ & 4,47 & $a$ & 33 & a & 21,78 & $b$ & 15,01 & $b$ \\
\hline G3 & 2,06 & $b$ & 1,29 & $\mathrm{~b}$ & 3,91 & $c$ & 29 & b & 22,77 & b & 11,73 & $b$ \\
\hline G4 & 2,14 & $b$ & 1,39 & $b$ & 3,47 & $d$ & 43 & $a$ & 24,72 & $a$ & 14,49 & $b$ \\
\hline G5 & 1,93 & $b$ & 1,45 & $b$ & 4,36 & $a$ & 32 & $b$ & 23,59 & $b$ & 13,67 & $b$ \\
\hline G6 & 2,41 & $a$ & 1,46 & $\mathrm{~b}$ & 4,21 & $b$ & 39 & a & 25,92 & a & 19,75 & a \\
\hline G7 & 2,22 & $b$ & 1,43 & $b$ & 3,47 & $d$ & 40 & $a$ & 23,11 & $b$ & 15,24 & $b$ \\
\hline G8 & 2,04 & $b$ & 1,55 & $a$ & 3,47 & $d$ & 18 & b & 25,18 & a & 14,90 & $b$ \\
\hline G9 & 2,52 & $a$ & 1,33 & $b$ & 3,41 & d & 38 & a & 26,55 & $a$ & 18,57 & a \\
\hline G10 & 2,16 & $b$ & 1,44 & $b$ & 3,93 & $b$ & 25 & $b$ & 21,35 & $b$ & 12,10 & $b$ \\
\hline$T$ & 2,14 & $b$ & 1,52 & $a$ & 4,51 & $a$ & 27 & $b$ & 25,92 & a & 16,01 & $b$ \\
\hline DMS- Tukey(1\%) & 0,63 & & 0,41 & & 0,87 & & 21 , & & 6,96 & & 12,24 & \\
\hline DMS- Tukey(5\%) & 0,55 & & 0,36 & & 0,77 & & 19, & & 6,16 & & 10,84 & \\
\hline
\end{tabular}


Menezes et al. (2016) / Comportamento Per se de híbridos...

Tabela 8. Altura da planta (ALT - m), diâmetro do colmo (DC - cm), largura da lâmina foliar (LL - cm), número de perfilhos por metro linear, percentagem de matéria seca (\%MS) e produção de matéria seca (PMS - t.ha ${ }^{-1}$ ) em genótipos de capim-elefante na estação seca (Campos dos Goytacazes, RJ, 2013).

\begin{tabular}{|c|c|c|c|c|c|c|c|c|c|c|c|c|}
\hline \multirow{2}{*}{$\begin{array}{c}\text { Genó- } \\
\text { tipos }\end{array}$} & \multicolumn{11}{|c|}{ Características ${ }^{1 /}$} & \\
\hline & \multicolumn{2}{|c|}{$\begin{array}{l}\text { ALT } \\
\text { (m) }\end{array}$} & \multicolumn{2}{|c|}{$\begin{array}{l}\mathrm{DC} \\
(\mathrm{cm})\end{array}$} & \multicolumn{2}{|c|}{$\begin{array}{c}\mathrm{LL} \\
(\mathrm{cm})\end{array}$} & \multicolumn{2}{|c|}{ NP } & \multicolumn{2}{|c|}{$\begin{array}{c}\% M S \\
(\%)\end{array}$} & \multicolumn{2}{|l|}{ PMS } \\
\hline $\mathrm{Hl}$ & 1,96 & $a$ & 1,38 & $\mathrm{~b}$ & 3,64 & c & 27 & $\mathrm{~b}$ & 18,72 & $\mathrm{~b}$ & 5,69 & $a$ \\
\hline $\mathrm{H} 2$ & 1,46 & $b$ & 1,37 & $b$ & 3,69 & C & 19 & $\mathrm{~b}$ & 22,00 & a & 3,35 & a \\
\hline $\mathrm{H} 3$ & 1,88 & $a$ & 1,57 & $a$ & 3,51 & c & 29 & $b$ & 19,19 & $\mathrm{~b}$ & 5,56 & $a$ \\
\hline $\mathrm{H} 4$ & 1,86 & $a$ & 1,30 & $b$ & 3,41 & c & 41 & $a$ & 18,51 & $\mathrm{~b}$ & 6,99 & $a$ \\
\hline H5 & 1,96 & $a$ & 1,48 & $a$ & 3,83 & C & 23 & $\mathrm{~b}$ & 24,43 & $a$ & 7,41 & a \\
\hline $\mathrm{H} 6$ & 2,02 & $a$ & 1,59 & $a$ & 3,68 & c & 25 & $\mathrm{~b}$ & 23,13 & $a$ & 6,26 & $a$ \\
\hline $\mathrm{H} 7$ & 2,16 & $a$ & 1,75 & $a$ & 3,36 & c & 39 & $a$ & 19,53 & $b$ & 10,33 & \\
\hline $\mathrm{H} 8$ & 1,85 & $a$ & 1,49 & $a$ & 3,53 & $c$ & 41 & $a$ & 26,54 & $a$ & 11,24 & \\
\hline $\mathrm{H} 9$ & 1,65 & $b$ & 1,43 & $a$ & 4,04 & $b$ & 32 & $a$ & 14,26 & $b$ & 4,46 & a \\
\hline $\mathrm{H} 10$ & 1,96 & $a$ & 1,60 & $a$ & 3,65 & $c$ & 29 & $b$ & 23,87 & $a$ & 8,20 & a \\
\hline $\mathrm{H} 11$ & 1,96 & $a$ & 1,50 & $a$ & 3,74 & C & 31 & $a$ & 21,10 & $b$ & 5,60 & a \\
\hline $\mathrm{H} 12$ & 1,90 & $a$ & 1,23 & $b$ & 2,90 & $d$ & 43 & $a$ & 18,82 & $b$ & 6,69 & a \\
\hline $\mathrm{H} 13$ & 1,92 & $a$ & 1,48 & $a$ & 4,89 & $a$ & 33 & $a$ & 27,05 & $a$ & 7,60 & a \\
\hline $\mathrm{H} 14$ & 1,67 & $b$ & 1,32 & $b$ & 3,81 & C & 39 & $a$ & 20,17 & $b$ & 6,92 & a \\
\hline $\mathrm{H} 15$ & 1,92 & $a$ & 1,46 & $a$ & 4,00 & $b$ & 38 & $a$ & 18,07 & $b$ & 5,92 & a \\
\hline $\mathrm{H} 16$ & 2,00 & $a$ & 1,36 & $b$ & 3,36 & $c$ & 22 & $b$ & 21,75 & $a$ & 4,82 & a \\
\hline $\mathrm{H} 17$ & 1,92 & $a$ & 1,68 & $a$ & 3,46 & C & 37 & a & 19,48 & $b$ & 9,71 & a \\
\hline $\mathrm{H} 18$ & 1,62 & $b$ & 1,11 & $b$ & 2,97 & $d$ & 35 & $a$ & 25,40 & $a$ & 7,22 & a \\
\hline $\mathrm{H} 19$ & 1,93 & $a$ & 1,76 & $a$ & 3,46 & c & 37 & $a$ & 19,07 & $b$ & 6,54 & $a$ \\
\hline $\mathrm{H} 2 \mathrm{O}$ & 1,88 & $a$ & 1,43 & $a$ & 3,48 & $c$ & 23 & $b$ & 26,81 & $a$ & 5,63 & a \\
\hline $\mathrm{H} 21$ & 1,83 & $a$ & 1,61 & $a$ & 3,62 & c & 28 & $b$ & 22,69 & $a$ & 8,22 & a \\
\hline $\mathrm{H} 22$ & 1,62 & $b$ & 1,62 & $a$ & 3,56 & c & 39 & $a$ & 15,30 & $b$ & 4,46 & $a$ \\
\hline $\mathrm{H} 23$ & 1,73 & $b$ & 1,29 & $b$ & 2,86 & $d$ & 23 & $b$ & 20,92 & $b$ & 4,60 & a \\
\hline $\mathrm{H} 24$ & 2,23 & $a$ & 1,73 & $a$ & 3,45 & c & 23 & $b$ & 19,09 & $b$ & 5,71 & a \\
\hline $\mathrm{H} 25$ & 1,96 & $a$ & 1,95 & $a$ & 5,01 & $a$ & 36 & $a$ & 15,74 & $b$ & 6,65 & a \\
\hline G1 & 1,87 & $a$ & 1,07 & $b$ & 4,15 & $b$ & 22 & $b$ & 26,92 & $a$ & 7,19 & $a$ \\
\hline G2 & 1,88 & $a$ & 1,18 & $b$ & 4,31 & $b$ & 34 & $a$ & 19,42 & $b$ & 7,81 & a \\
\hline G3 & 1,65 & $b$ & 1,45 & $a$ & 4,00 & $b$ & 32 & $a$ & 23,43 & $a$ & 6,96 & a \\
\hline G4 & 1,75 & $b$ & 1,14 & $b$ & 2,97 & $d$ & 17 & $b$ & 18,27 & $b$ & 2,81 & a \\
\hline G5 & 1,73 & $b$ & 1,82 & $a$ & 4,15 & $b$ & 34 & $a$ & 25,76 & $a$ & 6,73 & a \\
\hline G6 & 2,07 & $a$ & 1,56 & $a$ & 3,54 & $c$ & 21 & $b$ & 25,00 & $a$ & 7,43 & a \\
\hline G7 & 1,58 & $b$ & 1,62 & $a$ & 3,09 & $d$ & 36 & a & 17,95 & $b$ & 5,69 & a \\
\hline G8 & 1,67 & $b$ & 0,75 & $b$ & 1,38 & e & 16 & $b$ & 10,84 & $b$ & 2,10 & a \\
\hline G9 & 1,72 & $b$ & 1,21 & $b$ & 3,21 & $d$ & 46 & a & 21,15 & $b$ & 5,79 & a \\
\hline G10 & 1,70 & $b$ & 1,53 & $a$ & 3,55 & $c$ & 19 & $b$ & 14,11 & $b$ & 2,22 & $a$ \\
\hline$T$ & 2,30 & $a$ & 1,73 & $a$ & 4,00 & $b$ & 19 & $b$ & 27,33 & $a$ & 8,37 & a \\
\hline DMS- Tukey (1\%) & 0,59 & & 1,03 & & 1,7 & & 30 & & 19,2 & & 9,59 & \\
\hline DMS- Tukey (5\%) & 0,79 & & 0,23 & & 1,5 & & 28 & 9 & 17,0 & & 8,49 & \\
\hline
\end{tabular}

${ }^{*}$ Médias seguidas de mesma letra não diferem entre si pelo teste de Scott-knott a $5 \%$ de probabilidade. 


\section{Referências}

Bernini, C.S., Paterniani, M.E. A.G.Z. 2012. Estimativas de parâmetros de heterose em híbridos de populações $F_{2}$ de milho. Pesquisa Agropecuária Tropical 42: 56-62.

Carneiro, M.S.S., Souza, P. ., Peixoto, M.J.A., Sales, R.O., Feitosa, J.V. 2006. Efeito do consórcio de capim-elefante com leucena na produção de forragem. Revista Caatinga 19: 51-55.

Cavalcante, M., Lira, M.A., Santos, M.V.F., Santoro, K.R., Ferreira, R.L.C., Leão Neto, J.M.C. 2013 Potencial produtivo de Pennisetum spp. Sob níveis de nitrogênio na zona da mata de Pernambuco. Archivos de Zootecnia 62: 501-512.

Cunha, M.V., Lira, M.A., Santos, M.V.F., Freitas, E.V., Dubeux Junior, J.C.B., Mello, A.C.L., Martins, K.G.R. 2011. Revista Brasileira de Zootecnia 40: 482-488.

Cruz, C.D., Regazzi, A. ., Carneiro, P.C.S. 2012. Métodos biométricos aplicados ao melhoramento genético. UFV, Viçosa, Brasil. $514 \mathrm{p}$.

Cruz, C.D. 2013. GENES - a software package for analysis in experimental statistics and quantitative genetics. Acta Scientiarum. Agronomy 35: 271 276.

Daher, R.F., Pereira, A.V., Pereira, M.G., Lédo, F.J.S., Amaral Junior, A.T., Rocabado, J.M.A., Ferreira, C.F., Tardin, F.D. 2004. Análise de trilha de caracteres forrageiros do capim-elefante (Pennisetum purpureum Schum.). Ciência Rural 34: 1531-1535.

Faria, A.P., Moda-Cirino, V., Buratto, J.S., Silva, C.F.B., Destro, D. 2009. Interação genótipo $x$ ambiente na produtividade de grãos de linhagens e cultivares de feijão linhagens e cultivares de feijão. Acta Scientiarum. Agronomy 31: 579-585.

Ferreira, G.D.G., Santos, M.V.F., Lira, M.A., Melo A.C.L., Almeida, O.C., Ribeiro, C.R., Oliveira, R.L., Palmieri, A.D. 2013. Quantitative and qualitative characteristics of elephant grass (Pennisetum purpureum Schum) clones in the semi-arid lands of Pernambuco (Brazil). Revista Colombiana de Ciências Pecuarias 26: 15-23.

Flores, R.A., Urquiaga, S., Alves, B.J.R., Collier, L.S., Boddey, R.M. 2012. Yield and quality of elephant grass biomass produced in the Cerrados region for bioenergy. Engenharia Agrícola 32: 831-839.

Gardner, C.O., Eberhart, S. A. 1966. Analysis and interpretation of the variety cross diallel and related populations. Biometrics 22: 439-452.

Gomes, F.J.B., Colodette, J.L., Burnet, A., Batalha,
L.A.R., Barbosa, B.M. 2013. Potential of elephant grass for pulp production. Bioresources 8: 43594379.

Ibrahim, N., Kamarudin, S.K., Minggu, L.J. 2014. Biofuel from biomass via photo-electrochemical reactions: An overview. Journal of Power Sources 259: 33-42.

Lemus, R, Brummer, E.C, Moore, K.J, Molstad, N.E, Burras, C.L, Barker, M.F. 2002. Biomass yield and quality of 20 switchgrass populations in southern lowa, USA: Biomass \& Bioenergy 23: 433-442.

Lima, R.S.N, Daher, R.F., Gonçalves, L.S.A., Rossi, D.A., Amaral Júnior, A.T., Pereira, M.G., Lédo, F.J.S. 2011. RAPD and ISSR markers in the evaluation of genetic divergence among accessions of elephant grass. Genetics and Molecular Research 10: 1304-1313.

Morais, R.F., Souza, B.J., Leite, J.M., Soares, L.H.B., Alves, B.J.R., Boddey, R.M., Urquiaga, S. 2009. Elephant grass genotypes for bioenergy production by direct biomass combustion. Pesquisa Agropecuária Brasileira 44: 133-140.

Morais, R.F., Quesada, D.M., Reis, V.M., Urquiaga, S., Alves, B.J.R., Boddey, R.M. 2011 . Contribution of biological nitrogen fixation to Elephant grass (Pennisetum purpureum Schum.). Plant and Soil 349: 1-12.

Price, D.L., Casler, M.D. 2014. Predictive relationships between plant morphological traits and biomass yield in switchgrass. Crop Science 54: 2637-645.

Rossi, D. A. 2010. Avaliação morfoagronômica e da qualidade da biomassa de acessos de capim-elefante (Pennisetum purpureum Schum.) para fins energéticos no norte fluminense. $66 \mathrm{p}$. Dissertação (Mestrado) - Universidade Estadual do Norte Fluminense Campos dos Goytacazes, Brasil.

Samson, R., Mani, S., Boddey, R. M., Sokhansanj, S., Quesada, D.M., Urquiaga, S., Reis, V., Lem, C. $\mathrm{H}$. 2005. The potential of $\mathrm{C}_{4}$ perennial grasses for developing a global bioheat industry. Critical Reviews in Plant Sciences 24: 461-495.

Silva, M.A. 2008. Interação genótipo x ambiente e estabilidade fenotípica de cana-de-açúcar em ciclo de cana de ano. Bragantia 67: 109-117.

Silva, M.A., Lira, M.A., Santos, M.V.F., Dubeux Junior, J.C.B., Cunha, M.V., Freitas, E.V. 2008. Análise de trilha em caracteres produtivos de Pennisetum sob corte em Itambé, Pernambuco. Revista Brasileira de Zootecnia 37: 1185-1191.

Silva, A.L.C., Santos, M.V.F., Dubeux Júnior, J.C.B., Lira, M.A., Ferreira, R.L.C., Freitas, E.V., Cunha, M.V., Silva, M.C. 2010. Variabilidade e 
Menezes et al. (2016) / Comportamento Per se de híbridos...

herdabilidade de caracteres morfológicos em clones de capim-elefante na Zona da Mata de Pernambuco. Revista Brasileira Zootecnia 39: 2132-2140.

Souza Sobrinho F., Pereira A.V., Ledo, F.J.S., Botrel, M.A., Oliveira, J.S., Xavier, D. F. 2005. Avaliação agronômica de híbridos interespecíficos entre capim-elefante e milheto. Pesquisa Agropecuária Brasileira 40: 873-880.

Teixeira Vitor, C.M., Fonseca, D.M., Cóser, A.C., Martins, C.E., Nascimento Júnior, D., Ribeiro Júnior, J.I. 2009. Produção de matéria seca e valor nutritivo de pastagem de capim-elefante sob irrigação e adubação nitrogenada. Revista Brasileira Zootecnia 38: 435-442.

Zhang, X., GU, H., Ding, C., Zhong, X., Zang, J., $X U, N .2010$. Path coefficient and cluster analyses of yield and morphological traits in Pennisetum purpureum. Tropical Grassland 44: 95-102. 